\title{
ESTABILIZAÇÃO DA TUTELA PROVISÓRIA
}

\author{
Dissertação de Mestrado
}

Orientador: Prof. Dr. José Carlos Baptista Puoli

\section{UNIVERSIDADE DE SÃO PAULO}

FACULDADE DE DIREITO

São Paulo - SP 



\section{ANWAR MOHAMAD ALI}

\section{ESTABILIZAÇÃO DA TUTELA PROVISÓRIA}

Dissertação apresentada à Banca Examinadora do Programa de Pós-Graduação em Direito, da Faculdade de Direito da Universidade de São Paulo, como exigência parcial para a obtenção do título de Mestre em Direito, na área de concentração Direito Processual, sob orientação do Prof. Dr. José Carlos Baptista Puoli.

\section{UNIVERSIDADE DE SÃO PAULO}

\section{FACULDADE DE DIREITO}

São Paulo - SP 


\section{Catalogação da Publicação}

Serviço de Processos Técnicos da Biblioteca da

Faculdade de Direito da Universidade de São Paulo

Ali, Anwar Mohamad.

Estabilização da tutela provisória/Anwar Mohamad Ali. -- São Paulo: USP/Faculdade de Direito, 2019.

195 p.

Dissertação (Mestrado) - Faculdade de Direito, Universidade de São Paulo, São Paulo, 2018.

Orientador: Prof. Dr. José Carlos Baptista Puoli.

1. Processo civil. 2. Estabilização. 3. Tutela provisória. I. Puoli, José Carlos Baptista, orient. II. Título. 
Aprovado em:

BANCA EXAMINADORA:

Professor(a):

Instituição:

Assinatura:

Professor(a):

Instituição:

Assinatura:

Professor(a):

Instituição:

Assinatura: 



\section{AGRADECIMENTOS}

Após uma longa e difícil jornada, é hora de agradecer. Sem Deus nada disso teria sido possível. Agradeço a todos que, mesmo não mencionados expressamente nessas breves linhas, foram importantes nessa caminhada.

Ao meu orientador, Prof. Puoli, pela oportunidade de abrir as portas do Largo São Francisco, por todas as reuniões e discussões. Certamente os ensinamentos serão levados para toda a vida. Aos demais professores do Departamento de Direito Processual pelas aulas ministradas que muito contribuíram com meu crescimento acadêmico. Não posso deixar de lembrar dos Profs. Assistentes, em especial do Bruno Vasconcelos Carrilho Lopes, Fernando Fontoura da Silva Cais, Clarisse Frechiani Lara Leite e Daniel Penteado de Castro.

Aos amigos e funcionários da Faculdade de Direito da Universidade de São Paulo pela acolhida durante esses anos.

À minha família pelos esforços que me permitiram seguir meus sonhos.

À Natalia, pelo amor, paciência e dedicação nos períodos de felicidade e tristeza. Obrigado por estar sempre ao meu lado.

E, por fim, um agradecimento especial ao meu pai. Não pude lhe dar o último abraço. Um dia nos reencontraremos. 



\section{RESUMO}

Anwar Mohamad Ali. Estabilização da tutela provisória. 195 p. Dissertação de Mestrado Faculdade de Direito, Universidade de São Paulo, São Paulo, 2019.

O trabalho analisa os requisitos, características e principais contornos que envolvem a estabilização da tutela provisória no Código de Processo Civil de 2015. Tratando-se de tema novo no sistema jurídico brasileiro, buscou-se avaliar, inicialmente, o histórico evolutivo das tutelas provisórias no Brasil, as anteriores propostas de estabilização e a existência de institutos semelhantes em outros países, especialmente França, Itália, Portugal e Argentina; entre esses, os destaques são os référés do direito francês e a tutela sumária de instrumentalidade atenuada do direito italiano. A partir de então foi possível traçar a razão pela qual o legislador optou por prever a possibilidade de estabilização, o que auxiliou na resolução de diversos problemas práticos e teóricos sobre a aplicação dessa técnica processual. Analisou-se o procedimento de requerimento de tutelas urgentes em caráter antecedente, além dos requisitos para o reconhecimento da estabilização, consequências da inércia das partes, avaliando-se os meios que impediriam a extinção do processo, a possibilidade de anulação, revisão ou modificação por meio de uma ação específica, cujas características também foram estudadas. Em seguida, e tendo como referência principal os motivos que levaram o legislador a introduzir a estabilização no ordenamento jurídico brasileiro, foram analisadas diversas situações específicas envolvendo a sua possível aplicação. Observou-se que a estabilização tem sentido nos casos em que ambas as partes estão satisfeitas com o provimento provisório concedido, tornando eventualmente desnecessário o prosseguimento do processo, mas que não é capaz de fazer coisa julgada material. Por fim, na tentativa de trazer maior segurança jurídica, esclarecendo as discussões e consolidando as diretrizes traçadas no trabalho, fez-se um esboço de uma proposta de lege ferenda.

Palavras-chave: Código de Processo Civil. Tutela provisória. Estabilização. Tutela antecipada. 



\begin{abstract}
Anwar Mohamad Ali. Interim protection stabilization. 195 p. Master dissertation - Faculty of Law, University of São Paulo, São Paulo, 2019.

This work analyzes the requirements, characteristics, and main contours that involve the interim protection stabilization in the Code of Civil Procedure of 2015. Since this is a new topic in the Brazilian legal system, the present study sought, initially, to evaluate the evolutionary history of the interim protection in Brazil, the previous stabilization proposals, and the existence of similar institutes in other countries, particularly France, Italy, Portugal, and Argentina - among these, the highlights are the référés of French law and the summary protection of attenuated instrumentality of Italian law. From this evaluation, it was possible to trace the reason why the legislator chose to provide for the possibility of stabilization, which helped in the resolution of several practical and theoretical problems regarding the application of this procedural technique. The procedure for requesting immediate injunctions in an antecedent character was analyzed, in addition to the requirements for the recognition of stabilization, the results of the parties' inertia, the means that would prevent the extinction of the process, and the possibility of repeal, revision or modification of it by means of a specific action, whose characteristics were also evaluated. Subsequently, and having as main reference the reasons that led the legislator to introduce stabilization in the Brazilian legal system, several specific situations involving its possible application were analyzed. It has been observed that stabilization makes sense in cases where both parties are satisfied with the provisional provident granted, making possibly unnecessary the continuation of the process, being, however, not able to make res judicata. Finally, in an attempt to create greater legal certainty, clarifying the discussions and consolidating the guidelines outlined in this work, a lege ferenda proposal is drafted.
\end{abstract}

Keywords: Code of Civil Procedure. Interim protection. Stabilization. Preliminary injunction. 



\section{SUMÁRIO}

INTRODUÇÃO

1. BREVE HISTÓRICO DAS TUTELAS PROVISÓRIAS NO DIREITO BRASILEIRO

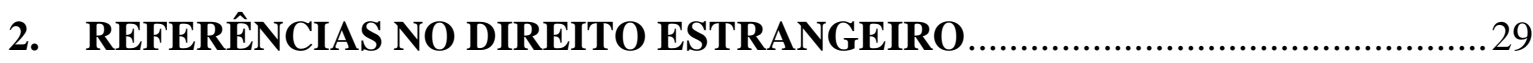

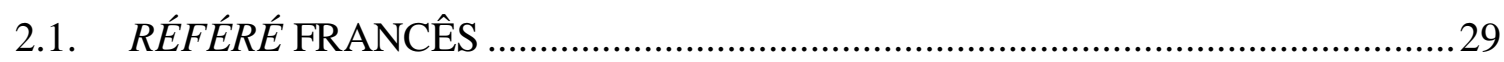

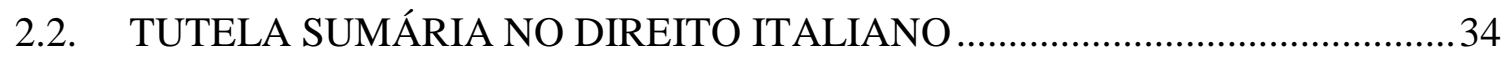

2.3. INVERSÃO DO CONTENCIOSO NO PROCESSO CIVIL PORTUGUÊS .......38

2.4. MEDIDAS AUTOSATISFACTIVAS NA ARGENTINA

3. TUTELAS PROVISÓRIAS NO CÓDIGO DE PROCESSO CIVIL/2015 45

3.1. TUTELA PROVISÓRIA DE URGÊNCIA 46

3.1.1. POSSIBILIDADE DE REQUERIMENTO EM CARÁTER ANTECEDENTE

3.1.2. TUTELA CAUTELAR ANTECEDENTE - GENERALIDADES

3.1.3. TUTELA ANTECIPADA ANTECEDENTE E ESTABILIZAÇÃO GENERALIDADES

3.2. TUTELA PROVISÓRIA DA EVIDÊNCIA

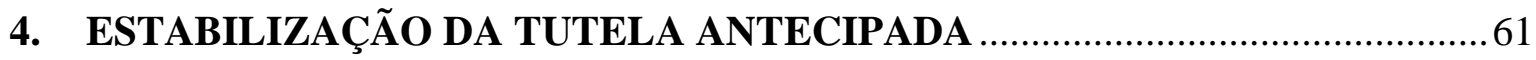

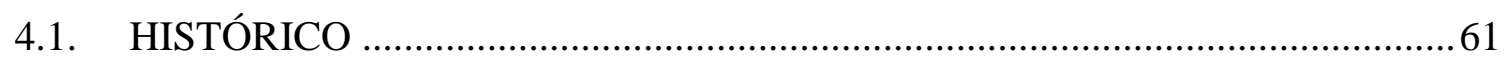

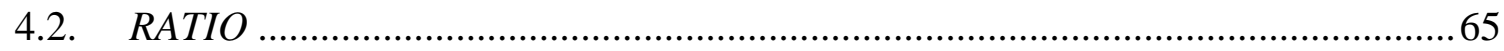

4.3. PRAZOS DE ADITAMENTO PARA CONFIRMAÇÃO DO PEDIDO DE

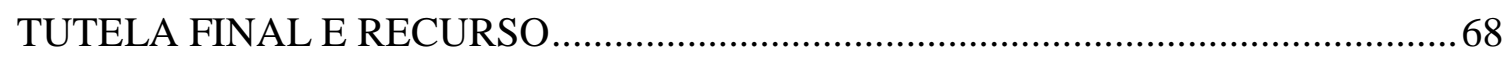

5. MEIOS PARA OBSTAR A ESTABILIZAÇÃO DA TUTELA PROVISÓRIA .. 79

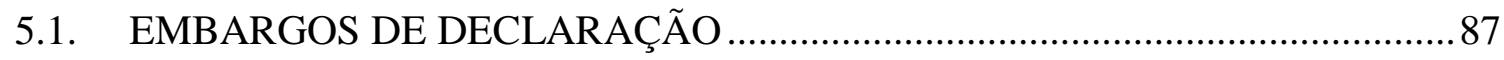

5.2. RECLAMAÇÃ

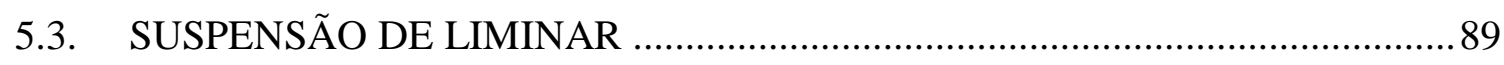

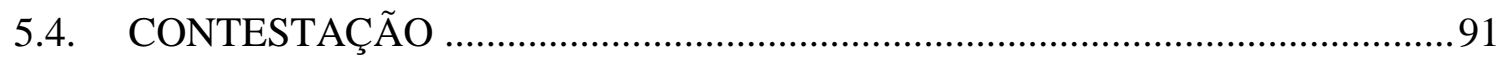



6. EXTINÇÃO DO PROCESSO PELA ESTABILIZAÇÃO .95

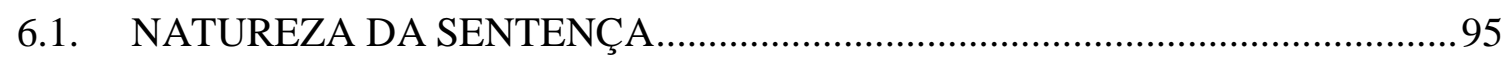

6.2. HONORÁRIOS ADVOCATÍCIOS E VERBAS SUCUMBENCIAIS.................99

7. A AÇÃO PARA REVER, REFORMAR OU INVALIDAR A TUTELA

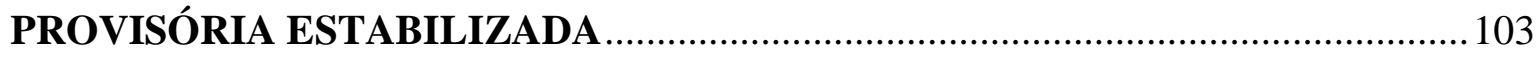

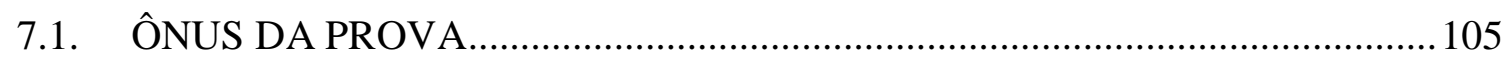

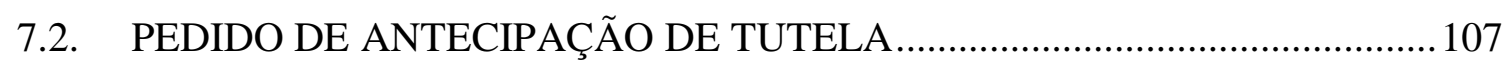

7.3. PRAZO DECADENCIAL OU PRESCRICIONAL? ........................................ 109

7.4. A (IN)EXISTÊNCIA DE COISA JULGADA: (IM)POSSIBILIDADE DE IMPUGNAÇÃO APÓS O PRAZO PREVISTO NO ART. 304, §5, DO CÓDIGO DE PROCESSO CIVIL DE 2015 ............................................................................... 110

8. INVESTIGAÇÃO DE OUTRAS POSSÍVEIS HIPÓTESES DE

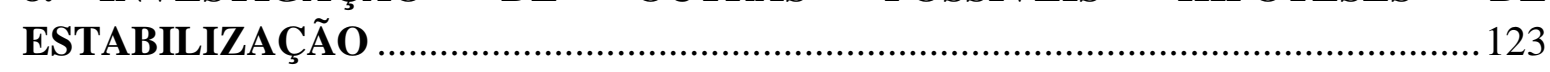

8.1. ESTABILIZAÇÃO DA TUTELA CAUTELAR ............................................ 123

8.1.1. MOTIVAÇÃO DA DECISÃO QUE DEFERE A TUTELA PROVISÓRIA: NECESSIDADE DE APONTAR O PROVIMENTO CONCEDIDO E CONTEÚDO DO MANDADO DE CITAÇÃO

8.1.2. FUNGIBILIDADE DAS TUTELAS PROVISÓRIAS E INTERESSE

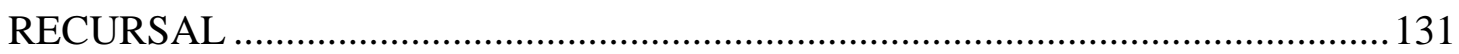

8.2. ESTABILIZAÇÃO DA TUTELA ANTECIPADA INCIDENTAL ................... 133

8.3. ESTABILIZAÇÃO DA TUTELA DA EVIDÊNCIA …................................... 140

8.4. ESTABILIZAÇÃO DA ANTECIPAÇÃO PARCIAL DA TUTELA .................. 144

8.5. ESTABILIZAÇÃO DA TUTELA PROVISÓRIA NOS TRIBUNAIS............... 147

8.6. ESTABILIZAÇÃO DA TUTELA PROVISÓRIA NOS PROCEDIMENTOS

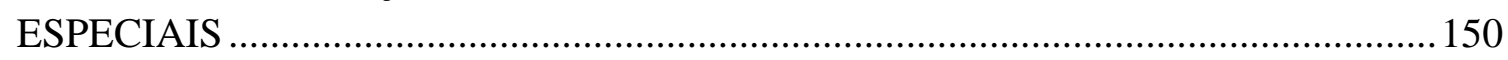

8.7. ESTABILIZAÇÃO CONTRA RÉU PRESO, INCAPAZ, CITADO POR HORA CERTA OU EDITAL 153

8.8. ESTABILIZAÇÃO EM CASOS DE LITISCONSÓRCIO E ASSISTÊNCIA .. 155

8.9. ESTABILIZAÇÃO EM FACE DA FAZENDA PÚBLICA ...............................159

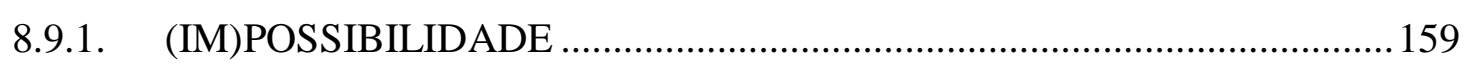

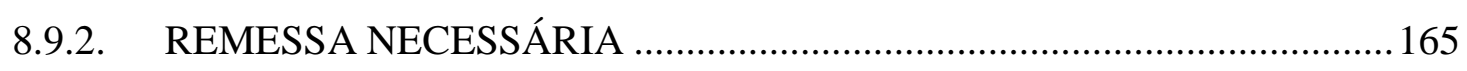

8.9.3. ESTABILIZAÇÃO EM FACE DO INSS: PARTICULARIDADES .......... 167 

9. PROPOSTA DE LEGE FERENDA

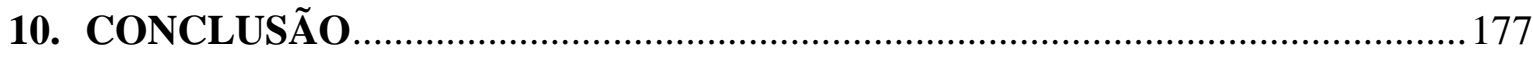

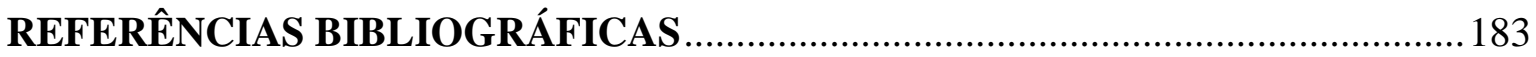





\section{INTRODUÇÃO}

O instituto da estabilização da tutela provisória é um dos mais inovadores temas do Código de Processo Civil de 2015. Sendo de tal maneira recente, e deveras complexo, ainda não há uma sistematização sobre seus contornos. Os primeiros doutrinadores que, $a$ priori, se arriscaram a tecer comentários sobre o tema já divergem em praticamente todos os pontos do instituto, sendo necessária uma abordagem mais aprofundada das suas características.

Não se trata, por óbvio, de mera discussão acadêmica, muito pelo contrário. A tutela provisória tem ganhado maior força no cotidiano forense a cada dia, de modo que, hodiernamente, tornou-se uma das maiores conquistas dos jurisdicionados que buscam a celeridade processual.

Portanto, diante da inovação temática e das controvérsias existentes, busca-se no presente trabalho analisar as principais questões que influenciam direta ou indiretamente a estabilização da tutela provisória, seus contornos, características, hipóteses de incidência e consequências.

Nesse sentido, nos propomos a enfrentar diversas questões para as quais o Código de Processo Civil de 2015 não traz, ao menos expressamente, soluções. Partindo do requerimento da tutela antecipada em caráter antecedente e de seu processamento, até os requisitos para a estabilização e suas consequências, praticamente nenhum ponto possui relevante grau de convergência, seja em âmbito doutrinário, seja em âmbito jurisprudencial.

Para que possamos compreender efetivamente do que se trata esse novo fenômeno, é importante buscar a sua ratio, ou seja, a razão pela qual a técnica foi introduzida no ordenamento jurídico pátrio, evitando que o regramento traga maiores problemas do que soluções.

Desse modo, inicialmente será feita uma breve análise histórica sobre como se desenvolveu o tratamento dedicado às tutelas provisórias no direito brasileiro até hoje, passando pelos Códigos de Processo Civil de 1939 e 1973, além da importante alteração efetuada pela Lei n. 8.952/94. 
Em seguida, cumpre investigar os países que utilizam técnicas semelhantes à da estabilização da tutela provisória e quais as características desse instituto naqueles ordenamentos jurídicos, especialmente França, Itália, Portugal e Argentina.

Não há a pretensão, contudo, de se fazer pormenorizada análise de direito comparado, o que demandaria estudo direcionado, e esse não é o escopo deste trabalho, mas é salutar avaliar os principais contornos de institutos assemelhados no direito estrangeiro, o que pode nos ajudar a compreender melhor seu surgimento e sua aplicação prática em nosso país.

Com isso, daremos início à análise das tutelas provisórias no Código de Processo Civil de 2015, divididas em duas espécies: tutela provisória de urgência e tutela provisória da evidência. Quanto às tutelas provisórias de urgência, estas são divididas em tutela provisória de urgência antecipada e tutela provisória de urgência cautelar, ambas podendo ser requeridas em caráter antecedente ou incidental.

Como a possibilidade de requerimento da tutela antecipada antecedente foi introduzida, ao menos expressamente, no Código de Processo Civil de 2015, salutar descrever algumas generalidades sobre esse novo tipo de técnica procedimental, além da interligação com o fenômeno da estabilização, sobre o qual também reservaremos linhas iniciais para tratar de suas características mais simples.

Com essas premissas, serão investigadas as raízes da estabilização no direito pátrio, inclusive os projetos de lei que, mesmo não tendo sido aprovados, previam seu cabimento e podem servir de norte para entender o texto legislativo vigente. Só então será analisada a razão pela qual o instituto foi introduzido em nosso ordenamento jurídico, talvez um dos pontos mais importantes do nosso estudo, o que poderá auxiliar na resolução de diversas controvérsias envolvendo sua aplicação.

A seguir, enfrenta-se, principalmente, a questão da aparente contradição entre a extinção do feito pela ausência de recurso do réu quanto à decisão que concede a tutela antecipada antecedente e a extinção do processo sem resolução do mérito pela ausência de aditamento da inicial, nessa mesma hipótese, para confirmação do pedido final. Trata-se de regras procedimentais que, se mal compreendidas, inviabilizam a própria aplicação da estabilização. 
Ponto fulcral do trabalho é a análise das atitudes que o réu pode tomar para obstar o reconhecimento da estabilização, importante requisito que tem causado intenso debate doutrinário. Além de propormos uma linha interpretativa que nos pareça mais correta, também buscaremos avaliar os pensamentos divergentes e sua utilidade no plano prático.

Será examinado, ainda, o passo seguinte à própria ocorrência da estabilização, qual seja, a natureza da decisão que extingue o processo pelo seu reconhecimento, bem como a (in)existência de condenação do réu em honorários advocatícios e custas processuais e, em caso positivo, os parâmetros para sua fixação.

Traçados esses limites, encerrado o processo no qual se reconheceu a estabilização, será possível avaliar os contornos da medida processual prevista para revisão, reforma ou invalidação da tutela antecipada cujos efeitos permanecem estáveis, tratando inicialmente dos seus aspectos gerais, e em seguida das regras aplicáveis ao ônus da prova e da (im)possibilidade de requerer tutela antecipada, sem olvidar da questão da natureza do prazo para sua propositura.

Não obstante, cumpre avaliar quais as consequências, processuais e factuais, caso essa ação não seja proposta no prazo legal, pois se de um lado a lei diz que essa tutela antecipada estabilizada não fará coisa julgada, de outro, prevê que seus efeitos só poderão ser revistos no prazo de dois anos. Sobre a questão, das mais tormentosas, propomo-nos a, sopesando toda a doutrina já produzida, atribuir o correto significado da norma.

Mas, sem prejuízo do acima deduzido, merece apreciação acerca da (im)possibilidade de se impugnar a tutela antecipada estabilizada após o prazo legal, e, se positiva a resposta, por qual mecanismo processual e em que momento.

Nos subcapítulos seguintes busca-se avaliar a aplicabilidade da estabilização a diversas situações fático-jurídicas que escapam às regras gerais especificamente trazidas pelo CPC/2015, como a viabilidade ou não de estabilização nas tutelas cautelar, da evidência e incidental; também nos casos de tutela antecipada parcial e deferida em grau recursal.

Quanto ao polo passivo, se seria possível a estabilização em caso de réu preso, incapaz, citado por hora certa e edital, além da temática quando estão em jogo os interesses da Fazenda Pública, com o acréscimo, neste último caso, da discussão sobre a 
(des)necessidade de remessa necessária (não é redundante?), caso se entenda admissível a estabilização contra os entes públicos.

Quanto aos procedimentos, se a estabilização, prevista na Parte Geral do Código, também pode ser aplicada naqueles especiais, sejam os regulados pelo CPC/2015 ou por leis extravagantes, com a análise, não exauriente, de alguns exemplos, como nos juizados especiais, nas leis da ação civil pública, locações e mandado de segurança.

Por fim, tivemos a ideia de submeter à apreciação uma proposta de lege ferenda, no intuito de solucionar os problemas enfrentados ao longo do trabalho.

Para avaliação das hipóteses cabíveis e alcance do resultado pretendido com o trabalho, houve o estudo de toda obra doutrinária atual de revelo sobre o Código de Processo Civil de 2015, especialmente quanto ao tema propriamente dito, além dos projetos apresentados no Congresso Nacional e da doutrina estrangeira nos países já indicados.

Não obstante, para auxílio na resolução das questões incidentais e das que porventura se relacionaram ao objeto central da pesquisa, foram analisadas também as obras doutrinárias do Código de Processo Civil de 1973, especialmente no que tange aos temas que envolvem a tutela provisória.

Por fim, também foi realizado um trabalho de pesquisa nos três maiores tribunais de justiça do Brasil ${ }^{1}$, a saber, São Paulo ${ }^{2}$, Rio de Janeiro e Minas Gerais, utilizando-se dos termos "estabilização" e "tutela" com a conjunção aditiva "e" no campo "Ementa". Obtidos os resultados, todos os acórdãos foram lidos. Excluídos aqueles que não possuem pertinência, os repetidos e os com fundamentação muito escassa, os demais foram citados em nota de rodapé nos respectivos capítulos.

\footnotetext{
${ }^{1}$ A informação sobre quais seriam os três maiores tribunais de justiça do Brasil foi extraída do relatório Justiça em Números 2018, do Conselho Nacional de Justiça, considerando-se os fatores "despesas totais; casos novos; processos pendentes; número de magistrados; número de servidores (efetivos, requisitados, cedidos e comissionados sem vínculo efetivo); e número de trabalhadores auxiliares (terceirizados, estagiários, juízes leigos e conciliadores)." A http://www.cnj.jus.br/files/conteudo/arquivo/2018/09/8d9faee7812d35a58cee3d92d2df2f25.pdf, p. 26-28.

${ }^{2}$ Com ampla pesquisa no âmbito do Tribunal de Justiça do Estado de São Paulo, em primeiro e segundo graus de jurisdição, vide: AUGUSTO DE ASSIS, Carlos. A estabilização da tutela antecipada e seus problemas revelados na prática. In: MARCATO, Ana Cândida Menezes; NETO, Elias Marques de Medeiros; DELlORE, Luiz; BARIONI, Rodrigo; MOLLICA, Rogerio; AMENDOEIRA JR., Sidnei; FERREIRA, William Santos (orgs.). Reflexões sobre o código de processo civil de 2015: uma contribuição dos membros do Centro de Estudos Avançados de Processo - CEAPRO. São Paulo: Verbatim, 2018, p. 145-157.
} 
Quanto aos tribunais superiores, parece-nos que, ao menos até o momento, há somente um julgado de relevo sobre o tema proferido no Superior Tribunal de Justiça, o qual também foi analisado e citado no tópico pertinente 


\section{CONCLUSÃO}

As tutelas provisórias foram ganhando força à medida que a sociedade evoluiu, demandando do Judiciário a pacificação dos crescentes conflitos que, cada vez mais, exigem célere solução.

Essa evolução culminou, no direito brasileiro, na edição da Lei n. 8.592/94, responsável por generalizar a possibilidade de pleitear tutelas satisfativas em caráter sumário e provisório, além de delinear a distinção delas com relação às tutelas cautelares, de caráter meramente acautelatório ou conservativo.

Nessa linha, o Código de Processo Civil de 2015 deu mais um passo: permitiu que tutelas de urgência fossem requeridas em caráter antecedente, ou seja, antes do ajuizamento do processo principal, bem como trouxe a possibilidade de tutelas sumárias satisfativas serem capazes de solucionar o litígio, ainda que não definitivamente, dispensando o prosseguimento do processo rumo à cognição exauriente.

Com o intuito de adaptar os procedimentos à tutela de direitos materiais ou situações da vida diferenciadas, há muito a doutrina brasileira já estudava a possibilidade de que uma tutela provisória fosse apta a solucionar o litígio e encerrar prematuramente a crise de direito material, o que inclusive deu ensejo a projetos de lei que, pelas mais variadas razões, acabaram não sendo aprovados, mas mantiveram acesa a discussão sobre sua viabilidade no ordenamento jurídico pátrio.

Tratando-se de instituto novo, a análise de técnicas semelhantes no direito estrangeiro, com o estudo de sua evolução histórica, bem como de problemas analíticos e pragmáticos enfrentados pela doutrina e jurisprudência nos países estudados, nos permitiu traçar as balizas nas quais se fundou a técnica da estabilização da tutela provisória adotada pela recente codificação processual civil.

Portanto, procuramos traçar as diretrizes históricas, sociológicas e jurídicas que levaram o legislador a introduzir a estabilização da tutela provisória no Código de Processo Civil de 2015. Ao descobrir a finalidade do instituto em estudo, foi possível trazer algumas 
respostas aos mais variados problemas e discussões que envolvem sua aplicabilidade prática.

Desse modo, o intuito foi apontar qual suporte fático-jurídico base levará o julgador ao reconhecimento da estabilização. Identificamos que a técnica da estabilização tem por escopo principal solucionar a crise de direito material que envolve as partes, ainda que provisoriamente, sem a necessidade de discutir a(s) questão(ões) em cognição exauriente.

Para tanto, é necessário que as partes se contentem com a provisória solução dada pelo julgador, tornando eventualmente dispensável o aprofundamento da discussão de fundo nos mesmos autos ou pelo ajuizamento de um processo principal. Ou seja, a estabilização tem razão de ser quando o comportamento das partes, ainda que omissivo, revele concordância com o acertamento provisório do direito discutido.

Daí porque, em nosso entender, a estabilização gira em torno da satisfação das partes com a tutela provisória concedida, a qual ocasionará a prematura extinção do processo, sem necessidade de prolongar a discussão. A solução passa, em grande medida, pela economia de tempo e recursos das partes, que não se veem animadas a prosseguir com um processo demorado e custoso, além de beneficiar também o Judiciário, com possível redução da litigiosidade ocasionada pela diminuição do número de processos em trâmite e pelo encurtamento do seu tempo de duração.

Traçadas essas balizas fundadas na conveniência das partes na instauração do processo de fundo, foi possível adentrar nas diversas discussões que envolvem a aplicabilidade da estabilização.

Assim, partindo das premissas acima estabelecidas, investigamos um dos principais pressupostos para o reconhecimento desse novo fenômeno, que é a ausência de oposição à tutela provisória concedida. A intepretação ampliativa acerca dos meios que têm o condão de evitar a estabilização surge, em um primeiro momento, da já mencionada finalidade da estabilização, que só tem razão de ser se ambas as partes demonstrem, ainda que por omissão, estarem satisfeitas com o provimento provisório deferido. 
Se qualquer delas pretender o prosseguimento da ação, a extinção do processo terá como inequívoca consequência a sua repropositura; se se entender que somente o agravo de instrumento impediria a estabilização, corre-se o risco de estimular sua interposição.

Mas não só por essa razão, a interpretação teleológico-sistemática deve prevalecer. Uma análise mais acurada do direito ao contraditório e à ampla defesa, princípios constitucionais norteadores do processo, também nos revela ser inconstitucional eventual exigência legal que torne obrigatória a interposição de um recurso para o exercício do direito de defesa. Uma vez dirigida determinada postulação ao Poder Judiciário, surge o direito do cidadão de ver seu pedido efetivamente analisado. Não se pode condicionar, pois, o direito de defesa à interposição de um recurso, o qual, aliás, exige o dispêndio de recursos financeiros.

A eventual necessidade de interpor recurso para a continuidade do processo também esbarra no princípio da isonomia processual. Enquanto basta ao autor aditar a inicial requerendo o prosseguimento do processo, não se faz necessário que o réu, sob guarida do tratamento paritário entre as partes, interponha um recurso para obter a mesma consequência prevista para a atitude do autor.

Concluímos, portanto, que o réu pode obstaculizar a estabilização por qualquer meio de insurgência ou impugnação. Contudo, como o escopo do trabalho foi analisar de maneira abrangente as demais linhas interpretativas possíveis, optamos por também investigar se a posição mais restritiva, calcada na literalidade da lei quanto ao termo "recurso", abarcaria outras formas impugnativas que, malgrado não se encaixem no conceito de recurso, também obstariam a estabilização, ainda que por via reflexa.

Desse modo, foram analisadas a reclamação, a contestação, o pedido de suspensão de liminar e os embargos de declaração.

Além disso, mostrou-se imprescindível investigar a natureza jurídica da sentença que extingue o processo pelo reconhecimento da estabilização, hipótese em que foram descobertas ao menos seis posições doutrinárias diferentes sobre o ponto. A proposta defendida neste trabalho baseia-se na necessidade de superar a existência de apenas duas espécies de sentença: as que extinguem o processo com e sem resolução de mérito. 
Em se tratando de estabilização, nenhuma dessas já conhecidas figuras serve para explicar a natureza jurídica da sentença que extingue esse procedimento. Se de um lado é certo que não houve resolução do mérito propriamente dito, de outro, tem-se que a tutela provisória continua a produzir efeitos mesmo após a extinção do processo, não havendo qualquer vício processual a reclamar a não resolução do mérito.

Assim, a melhor resposta é considerar que estamos diante de uma extinção sui generis, própria do reconhecimento do fenômeno estabilizatório.

Ainda quanto à extinção do processo, foi possível observar que, com relação aos honorários advocatícios, não há nada que diferencie a técnica estudada das regras comuns quanto à sua fixação. Não há norma que autorize sua não incidência, tampouco sua redução. A regra prevista para a ação monitória não pode ser aplicada por analogia, eis que, segundo ela, a redução só é possível caso o réu cumpra o mandado monitório no prazo legal. Para a ocorrência da estabilização, por outro lado, não há exigência de que a tutela provisória seja cumprida, de tal sorte que o suporte fático-jurídico de ambas é diverso.

Passada a fase da estabilização propriamente dita, o sistema processual civil pátrio, em consonância com o que se verificou em outros países, previu a possibilidade de revisar, modificar ou anular a tutela provisória, em um prazo máximo de dois anos. Sobrevindo tal prazo, os efeitos da tutela provisória não mais sofrerão alteração, o que não significa estarmos diante do fenômeno da coisa julgada.

O objetivo foi avaliar os contornos que envolvem essa ação revisional, cujo prazo para propositura é decadencial, bem como o seu principal aspecto: trata-se de ação considerada uma extensão ou desdobramento da ação antecedente, o que inequivocamente reflete em outras questões, como no ônus da prova, que permanecerá, em regra, com o autor da ação originária, e na possibilidade de requerer medidas urgentes em seu bojo.

Mais importante, entretanto, foi analisar a possível consequência decorrente do não ajuizamento dessa ação no prazo de dois anos. Pudemos concluir que a estabilização é uma figura jurídica nova quando se trata dos diversos graus ou níveis de estabilidade das decisões judiciais, não se confundindo com institutos já conhecidos como coisa julgada ou preclusão. 
Nesse sentido, além de a lei ser expressa ao afastar a ocorrência de coisa julgada na hipótese, não se vislumbra a existência do seu chamado efeito positivo, nem mesmo pode-se considerar que houve declaração de que o direito do autor existe. Contudo, como os efeitos da tutela provisória só poderiam ter sido afastados por meio daquela ação específica, a estabilização está mais relacionada ao que conhecemos por efeito negativo da coisa julgada.

Isso quer dizer, em resumo, que a relação jurídica subjacente pode ser discutida mesmo após o prazo de dois anos, desde que para a obtenção ou desfazimento de outros efeitos que não os já soberanamente estabilizados, ainda que o resultado do processo posterior seja incompatível com o anterior.

De todo modo, como o Código de Processo Civil de 2015 positivou a possibilidade de ajuizar a ação rescisória para desconstituir decisões que, mesmo sem apreciar o mérito, impossibilitem a repropositura da demanda, o qual é justamente o caso dos efeitos soberanamente estabilizados, não se pode descartar a admissibilidade de sua propositura caso presente alguma de suas hipóteses de cabimento.

Em linhas gerais, após tratarmos sobre os requisitos e contornos que envolvem a estabilização em geral, passamos a refletir sobre a (im)possibilidade de estabilização em outras hipóteses específicas que, pelos mais diversos motivos, possuem alguma peculiaridade que comportasse essa análise individualizada, mas sempre com os olhos voltados para as diretrizes antes traçadas. Buscou-se analisar a viabilidade da estabilização da tutela parcial, nos tribunais, em procedimentos especiais, nos casos de réu preso, incapaz, citado por hora certa ou edital, e também nas hipóteses de litisconsórcio e assistência.

Em caráter conclusivo, importante salientar que, considerando a ratio do instituto, plenamente possível aplicá-lo também nas hipóteses de tutela antecipada incidental e na tutela da evidência. Ambas têm caráter de satisfatividade que, aliado ao contentamento do autor e à ausência de insurgência do réu, e desde que deferidas antes da apresentação de defesa, sedimentam o arcabouço fático-jurídico apto a ensejar o reconhecimento da estabilização com a consequente extinção prematura do processo. 
De comum, e para evitar decisões-surpresa, basta que o réu tenha ciência da possível estabilização, caso não se insurja contra o deferimento da tutela provisória, e que o autor não se manifeste requerendo a continuidade do processo.

No que se refere à possibilidade de estabilização da tutela cautelar, a resposta é diversa. Não possuindo o atributo da satisfatividade, não há como pretender estabilizá-la, já que é sempre dependente de um processo principal em que haverá o verdadeiro acertamento do direito material.

Vale destacar a possibilidade de estabilizar a tutela provisória em face da Fazenda Pública, com exceção das hipóteses em que seja imprescindível a expedição de precatório, pois nesse caso há exigência constitucional de trânsito em julgado, o qual não se verifica na estabilização. Sequer há necessidade de submeter a sentença à remessa necessária, já que não é propriamente contrária à Fazenda Pública, a qual, aliás, também poderá se insurgir por meio da ação revisional específica.

Por fim, procuramos traçar um esboço de uma proposta de lege ferenda cujo objetivo é dissipar as discussões envolvendo o tema, conciliando as linhas interpretativas que o trabalhou investigou, e trazendo maior segurança jurídica ao tornar mais claros seus aspectos. 


\section{REFERÊNCIAS BIBLIOGRÁFICAS}

ALENCAR, Hermes Arrais. Benefícios previdenciários. $4^{\mathrm{a}}$ ed. São Paulo: Universitária de Direito, 2009.

ALI, Anwar Mohamad. Meios para superação da prova diabólica: da distribuição dinâmica do ônus da prova aos standards probatórios. Revista Forense, vol. 424/2016.

ALVIM, Angélica Arruda; ARAKEN DE ASSIS; ALVIM, Eduardo Arruda; LEITE, George Salomão (coords.). Comentários ao código de processo civil. $2^{\mathrm{a}}$ ed. São Paulo: Saraiva, 2017.

ALVIM, Arruda. Manual de direito processual civil: teoria geral do processo e processo de conhecimento. 17 . São Paulo: Ed. Revista dos Tribunais, 2017.

ALVIM, Eduardo Arruda. Tutela provisória. $2^{\mathrm{a}}$ ed. São Paulo: Saraiva, 2017. Antecipação da tutela. Curitiba: Juruá, 2009.

ALVIM, J.E. Carreira. Tutela antecipada. $5^{\text {a }}$ ed. Curitiba: Juruá, 2006.

- Desvendando uma incógnita: a tutela antecipada antecedente e sua estabilização no novo Código de Processo Civil. Revista de Processo, vol. 259/2016.

AMADO, Frederico. Direito previdenciário. $5^{\mathrm{a}}$ ed. Salvador: Juspodivm, 2015.

AMARAL, Guilherme Rizzo. Comentários às alterações do Novo CPC. São Paulo: Ed. Revista dos Tribunais, 2015.

ANDRADE, Érico. A técnica processual da tutela sumária no direito italiano. Revista de Processo, vol. 179/2010.

ARAÚJO, José Henrique Mouta. Mandado de segurança. $6^{\mathrm{a}}$ ed. Salvador: Juspodivm, 2017.

ARMELIN, Donaldo. Tutela jurisdicional diferenciada. Revista de Processo, vol. 65/1992.

ASSIS, Araken de. Processo civil brasileiro. Parte geral: institutos fundamentais, vol. II, tomo II. São Paulo: Ed. Revista dos Tribunais, 2015.

- Antecipação de tutela. In: WAMBIER, Teresa Arruda Alvim (coord.). Aspectos polêmicos da antecipação de tutela. São Paulo: Ed. Revista dos Tribunais, 1997.

AUGUSTO DE ASSIS, Carlos. A antecipação de tutela e a sua estabilização. Novas perspectivas. In: BUENO, Cassio Scarpinella; NETO, Elias Marques de Medeiros; NETO, Olavo de Oliveira; CAZZOLINO DE OLIVEIRA, Patrícia Elias; LUCON, Paulo Henrique dos Santos (coords.). Tutela provisória no CPC: dos 20 anos de vigência do art. 273 do CPC/1973 ao CPC/2015. 2a ed. São Paulo: Saraiva Educação, 2018.

. A estabilização da tutela antecipada e seus problemas revelados na prática.

In: MARCATO, Ana Cândida Menezes; NETO, Elias Marques de Medeiros; DELLORE, 
Luiz; BARIONI, Rodrigo; MOLLICA, Rogerio; AMENDOEIRA JR., Sidnei; FERREIRA, William Santos (orgs.). Reflexões sobre o código de processo civil de 2015: uma contribuição dos membros do Centro de Estudos Avançados de Processo - CEAPRO. São Paulo: Verbatim, 2018.

Técnicas aceleratórias e devido processo legal. Revista Brasileira de Direito Processual, ano 24, n. 95.

Reflexões sobre os novos rumos da tutela de urgência e da evidência no Brasil a partir da Lei 13.105/2015. In: DIDIER JR., Fredie (coord. geral). Procedimentos especiais, tutela provisória e direito transitório. Coleção Novo CPC - Doutrina Selecionada. Salvador: Juspodivm, 2016.

.; LOPES, João Batista. Tutela provisória: tutela antecipada; tutela cautelar; tutela de evidência; tutela inibitória antecipada. Brasília: Gazeta Jurídica, 2018.

BARBOSA MOREIRA, José Carlos. Temas de direito processual. $2^{\mathrm{a}}$ ed. São Paulo: Saraiva, 1988.

6.

Ainda e sempre a coisa julgada. Doutrinas essenciais de processo civil, vol. Litisconsórcio unitário. Rio de Janeiro: Forense, 1972.

BARIONI, Rodrigo. Ação rescisória e recursos para os Tribunais Superiores. $2^{\mathrm{a}}$ ed. São Paulo: Ed. Revista dos Tribunais, 2013.

$105 / 2002$.

Efeito infringente dos embargos de declaração. Revista de Processo, vol.

A ação rescisória no novo CPC. Revista de Processo, vol. 207/2012.

Art. 966. In: WAMBIER, Teresa Arruda Alvim; DIDIER JR., Fredie; TALAMINI, Eduardo; DANTAS, Bruno (coords.). Breves comentários ao novo código de processo civil. São Paulo: Ed. Revista dos Tribunais, 2015.

Alguns apontamentos sobre a ação rescisória no projeto do novo Código de Processo Civil. Revista de Informação Legislativa, ano 48, n. 190, t. 2, abr/jun-2011.

BAUERMANN, Desirê. Estabilização da tutela antecipada. Revista Eletrônica de Direito processual - REDP. Volume VI. Periódico da Pós Graduação Stricto Sensu em Direito Processual da UERJ.

BEDAQUE, José Roberto dos Santos. In: BUENO, Cássio Scarpinella (coord.). Comentários ao código de processo civil, vol. 1. São Paulo: Saraiva, 2017.

Tutela cautelar e tutela antecipada: tutelas sumárias e de urgência (tentativa de sistematização). $5^{\text {a }}$ ed. São Paulo: Malheiros, 2009.

Tutela cautelar e tutela antecipada: tutelas sumárias e de urgência (tentativa de sistematização). $2^{\mathrm{a}}$ ed. São Paulo: Malheiros, 2001. 
Estabilização das tutelas de urgência. In: YARSHELL, Flávio Luiz; ZANOIDE DE MORAES, Maurício (orgs.) Estudos em homenagem a Ada Pellegrini Grinover. São Paulo: DPJ, 2005.

BEDUSCHI, Leonardo; HENCKEMAIER, Heidy Santos. Dois temas controvertidos sobre a estabilização da tutela antecipada antecedente. Revista de Processo Comparado, vol. $5 / 2017$.

BONATO, Giovanni. A estabilização da tutela antecipada de urgência no código de processo civil brasileiro de 2015 (uma comparação entre Brasil, França e Itália). Revista de Processo, vol. 273/2017.

; GOMES DE QUEIROZ, Pedro. Os référés no ordenamento francês. Revista de Processo, vol. 255/2016.

BONAVIDES, Paulo. Curso de direito constitucional. 19ª ed. São Paulo: Malheiros, 2006.

BONÍCIO, Marcelo José Magalhães. Princípios do processo no novo Código de Processo Civil. São Paulo: Saraiva, 2016.

. Notas sobre a tutela antecipada "parcial" na nova reforma do código de processo civil. Revista dos Tribunais, vol. 808/2003.

BONIZZI, Marcelo José Magalhães. Fundamentos da prova civil. São Paulo: Ed. Revista dos Tribunais, 2017.

BOTELHO DE MESQUITA, José Ignacio. A coisa julgada. Rio de Janeiro: Forense, 2004.

BUENO, Cassio Scarpinella. Curso sistematizado de direito processual civil, vol. 1: teoria geral do direito processual civil: parte geral do código de processo civil. $9^{a}$ ed. São Paulo: Saraiva Educação, 2018.

Tutela antecipada. $2^{\mathrm{a}}$ ed. São Paulo: Saraiva, 2007.

BUIKA, Heloisa Leonor. A ambiguidade da estabilização dos efeitos da tutela antecipada e a coisa julgada no novo Código de Processo Civil. Revista de Processo, vol. 267/2017.

BURIL DE MACÊDO, Lucas; PEIXOTO, Ravi. Tutela provisória contra a Fazenda Pública no CPC/2015. In: DIDIER JR., Fredie (coord. geral). Fazenda Pública. Coleção Repercussões do Novo CPC. $2^{\text {a }}$ ed. Salvador: Juspodivm, 2016.

CABRAL, Antonio do Passo. As estabilidades processuais como categoria incorporada ao sistema do CPC. In DIDIER JR., Fredie; CABRAL, Antonio do Passo (coords.) Coisa julgada e outras estabilidades processuais. Salvador: Juspodivm, 2018.

. A coisa julgada formal faz sentido no sistema do CPC/2015?. In: DIDIER JR., Fredie; CABRAL, Antonio do Passo (coords.). Coisa julgada e outras estabilidades processuais. Salvador: Juspodivm, 2018.

CALAMANDREI. Piero. Introdução ao estudo sistemático dos procedimentos cautelares. Trad. Carla Roberta Andreassi Bassi. Campinas: Servanda, 2000. 
CÂMARA, Alexandre Freitas. O novo processo civil brasileiro. $3^{\text {a }}$ ed. São Paulo: Atlas, 2017. . O novo processo civil brasileiro. São Paulo: Atlas, 2015.

; PEDRON, Flávio Quinaud; TOLENTINO, Fernando Lage. Tutelas provisórias no CPC 1973 e no CPC 2015: o quanto o novo tem de inovador? Revista de Processo, vol. 262/2016.

CAMBI, Eduardo; NEVES, Aline Regina das. Acesso à justiça, tutela antecipada e técnicas processuais. In: Procedimentos especiais, tutela provisória e direito transitório. Salvador: Juspodivm, 2015.

CARNEIRO, Athos Gusmão. Da antecipação de tutela. $7^{\mathrm{a}}$ ed. Rio de Janeiro: Forense, 2010.

CARNEIRO DA CUNHA, Leonardo. A fazenda pública em juízo. $13^{\mathrm{a}}$ ed. Rio de Janeiro: Forense, 2016.

- Natureza jurídica da reclamação constitucional. In: Aspectos polêmicos e atuais dos recursos cíveis e de outros meios de impugnação às decisões judiciais. São Paulo: Ed. Revista dos Tribunais, 2005.

CARNELUTTI, Francesco. Instituições do processo civil, vol. I. Campinas: Servanda, 1999.

CARRATTA, Antonio. La tutela sommaria in Europa - studi. Napoli: Jovene, 2012.

CASTRO, Daniel Penteado de. Antecipação de tutela sem o requisito da urgência: panorama geral e perspectivas no novo Código de Processo Civil. Salvador: Juspodivm, 2017.

CASTRO, Roberta Dias Tarpinian. O sentido de antecedente e a estabilização da tutela provisória antecipada. Revista de Processo, vol. 265/2017.

CAVALCANTI NETO, Antonio de Moura. Estabilização da tutela antecipada antecedente: tentativa de sistematização. In: DIDIER JR., Fredie (coord. geral). Coleção Grandes Temas do Novo CPC, vol. 6: Tutela provisória. Salvador: Juspodivm, 2016.

CÉSAR DE SOUZA, Artur. Tutela provisória: tutela de urgência e tutela de evidência. São Paulo: Almedina, 2016.

CHAINAIS, Cécile. La protection juridictionnelle provisoire dans le procès civil en droit français et italien. Paris: Dalloz, 2007.

CIANCI, Mirna. A estabilização da tutela antecipada como forma de desaceleração do processo (uma análise crítica). Revista de Processo, vol. 247/2015.

COSTA, Eduardo José da Fonseca. Art. 304. In: STRECK, Lenio Luiz; NUNES, Dierle; CARNEIRO DA CUNHA, Leonardo (orgs.). Comentários ao Código de Processo Civil. $2^{\mathrm{a}}$ ed. São Paulo: Saraiva, 2017. 
COSTA, Fábio Silva. Tutela antecipada, hermenêutica, acesso à justiça e princípio da efetividade processual. São Paulo: Juarez de Oliveira. 2000.

CRUZ E TUCCI, José Rogério. Ação monitória. $3^{\text {a }}$ ed. São Paulo: Ed. Revista dos Tribunais, 2001. vol. $786 / 2001$.

. Reflexões sobre a cumulação subsidiária de pedidos. Revista dos Tribunais,

DONIZETTI, Elpídio. Curso didático de direito processual civil. $21^{\mathrm{a}}$ ed. São Paulo: Atlas, 2018.

DOTTI, Rogéria. A estabilização da tutela antecipada no CPC de 2015: A autonomia da tutela sumária e a coisa julgada dispensável. In: LUCON, Paulo Henrique dos Santos (coord. et. al.). Processo em jornadas. Salvador: Juspodivm, 2016.

DORIA, Rogéria Dotti. A tutela antecipada em relação à parte incontroversa da demanda. $2^{a}$ ed. São Paulo: Ed. Revista dos Tribunais, 2003.

DIAS, Jean Carlos. Tutelas provisórias: tutelas de urgência e tutela de evidência. Salvador: Juspodivm, 2017.

DIDIER JR., Fredie; BRAGA, Paula Sarno; ALEXANDRIA DE OLIVEIRA, Rafael. Curso de direito processual civil: teoria geral da prova, direito probatório, decisão, precedente, coisa julgada e tutela provisória. 13 ${ }^{\mathrm{a}}$ ed. Salvador: Juspodivm, 2018.

- Estabilização da tutela provisória satisfativa e honorários advocatícios sucumbenciais. São Paulo: Revista do Advogado, vol. 126/2015.

DINAMARCO, Cândido Rangel. Nova era do processo civil. São Paulo: Malheiros, 2003.

. Instituições de direito processual civil, vol. 3. 6ª ed. São Paulo: Malheiros,

2009.

. Intervenção de terceiros. $5^{\text {a }}$ ed. São Paulo: Malheiros, 2009.

. Litisconsórcio. $8^{\mathrm{a}}$ ed. São Paulo: Malheiros, 2009.

Liebman e a cultura processual brasileira. In: YARSHELL, Flávio Luiz;

MORAES, Maurício Zanoide (orgs.). Estudos em homenagem à Professora Ada Pellegrini Grinover. São Paulo: DPJ, 2005.

; LOPES, Bruno Vasconcelos Carrilho. Teoria geral do novo processo civil. São Paulo: Malheiros, 2016.

DINIZ, Maria Helena. Compêndio de Introdução à ciência do Direito. 14a ed. São Paulo: Saraiva, 2001.

FAGUNDES, Cristiane Druve Tavares. Responsabilidade objetiva por dano processual. Rio de Janeiro: Lumen Juris, 2015. 
FENOLL, Jordi Nieva. Coisa julgada. Trad.: Antonio do Passo Cabral. São Paulo: Revista dos Tribunais, 2016.

FIORUCCI, Fabio. Tutela d'urgenza ex art. 700 c.p.c. Milano: Giuffrè, 2014.

FUX, Luiz. Tutela de segurança e tutela de evidência. São Paulo: Saraiva, 1996.

GAJARDONI, Fernando da Fonseca; DELLORE, Luiz; ROQUE, Andre Vasconcelos; DUARTE DE OLIVEIRA JR., Zulmar. Teoria geral do processo: comentários ao CPC de 2015: parte geral. $2^{\mathrm{a}}$ ed. São Paulo: Método, 2018.

GOMES, Frederico Augusto. A estabilização da tutela antecipada. São Paulo: Ed. Revista dos Tribunais, 2018.

GOMES DE QUEIROZ, Pedro. Mandado de segurança: propostas para duração razoável e efetividade. Salvador: Juspodivm, 2018.

GONZALEZ, Gabriel Araújo. A recorribilidade das decisões interlocutórias no código de processo civil de 2015. Salvador: Juspodivm, 2016.

GRECO, Leonardo. A Tutela de Urgência e a Tutela de Evidência no Código de Processo Civil de 2014/2015. Revista Eletrônica de Direito Processual, Ano 8, vol. XIV, jul./dez. 2014, disponível em <http://www.epublicacoes.uerj.br/index.php/redp/article/view/14541/11014>, acesso em 25.08.2015, às 22:08 horas.

. A tutela de urgência e a tutela da evidência no código de processo civil de 2015. In: DIDIER JR., Fredie (coord. geral). Procedimentos especiais, tutela provisória e direito transitório. $2^{\mathrm{a}}$ ed. Salvador: Juspodivm, 2016.

GODINHO, Robson. In: CABRAL, Antônio do Passo; CRAMER, Ronaldo (coords.). Comentários ao Novo Código de Processo Civil. Rio de Janeiro: Forense, 2015.

GRASSI DE GOUVEIA, Lúcio. In: ALVIM, Angélica Arruda; ARAKEN DE ASSIS; ALVIM, Eduardo Arruda; LEITE, George Salomão (coords.). Comentários ao código de processo civil. $2^{\mathrm{a}}$ ed. São Paulo: Saraiva, 2017.

GRINOVER, Ada Pellegrini. Tutela jurisdicional diferenciada: a antecipação e sua estabilização. In: O processo: estudos e pareceres. São Paulo: DPJ, 2009.

. Tutela jurisdicional diferenciada: a antecipação e sua estabilização. Revista de Processo, vol. 121/2005.

O difícil caminho da estabilização da tutela antecipatória. In: MENDES, Aluisio Gonçalves de Castro; WAMBIER, Teresa Arruda Alvim (orgs.). O processo em perspectiva: jornadas brasileiras de direito processual: São Paulo: Revista dos Tribunais, 2013.

Tutela antecipatória em processo sumário. In: ARMELIN, Donaldo (coord.). Tutelas de urgência e cautelar. Estudos em homenagem a Ovídio A. Baptista da Silva. São Paulo: Saraiva, 2010. 
HARTMANN, Rodolfo Kronemberg. A tutela provisória de urgência e os juizados especiais. In: DIDIER JR., Fredie (coord. geral). Juizados Especiais. Coleção Repercussões do novo CPC. Salvador: Juspodivm, 2015.

HILL, Flávia Pereira. Tutela provisória de urgência no novo Código de Processo Civil. In: JATAHY, Carlos Roberto; REZENDE DE ALMEIDA, Diogo Assumpção; AYOUB, Luiz Roberto (coords.). Reflexões sobre o novo código de processo civil. Rio de Janeiro: FGV Editora, 2016.

IBRAHIM, Fábio Zambitte. Curso de direito previdenciário. $20^{\mathrm{a}}$ ed. Rio de Janeiro: Impetus, 2015.

IOFRIDA, Giulia; SCARPA, Antonio. I nuovi procedimenti cautelari: doppo la Legge $n$. 80 del 2005, il D.L. n. 271 del 2005 e la Legge n. 51 del 2006. Milano: Giuffrè, 2006.

JORGE, Flávio Cheim. Teoria geral dos recursos cíveis. $7^{\text {a }}$ ed. São Paulo: Ed. Revista dos Tribunais, 2015.

LACERDA, Galeno. Comentários ao Código de Processo Civil. Vol. VIII, t. I. $3^{\text {a }}$ ed. Rio de Janeiro: Forense, 1987.

LAMY, Eduardo. Tutela provisória. São Paulo: Atlas, 2018.

. Flexibilização da tutela de urgência. $2^{\text {a }}$ ed. Curitiba: Juruá, 2008.

; LUIZ, Fernando Vieira. Estabilização da tutela antecipada no novo Código de Processo Civil. Revista de Processo, vol. 260/2016.

LEMOS, Vinicius Silva. A necessidade de separação da tutela provisória antecipada antecedente em duas espécies diferentes. Revista de Processo, vol. 266/2017.

LEONEL, Ricardo de Barros. Reclamação constitucional. São Paulo: Ed. Revista dos Tribunais, 2011.

Tutela jurisdicional diferenciada. São Paulo: Revista dos Tribunais, 2010.

LIEBMAN, Enrico Tullio. Eficácia e autoridade da sentença. Trad.: Alfredo Buzaid e Benvindo Aires. $3^{\text {a }}$ ed. Rio de Janeiro: Forense, 1984.

- Manual de Direito Processual Civil, v. I. $3^{\mathrm{a}}$ ed. Tradução e notas de Cândido Rangel Dinamarco. São Paulo: Malheiros, 2005.

LOPES, Bruno Vasconcelos Carrilho. Estabilização da tutela antecipada e coisa julgada. In: BUENO, Cassio Scarpinella; NETO, Elias Marques de Medeiros; NETO, Olavo de Oliveira; CAZZOLINO DE OLIVEIRA, Patrícia Elias; LUCON, Paulo Henrique dos Santos (coords.). Tutela provisória no CPC: dos 20 anos de vigência do art. 274 do CPC/1973 ao CPC/2015. São Paulo: Saraiva, 2016.

Tutela antecipada sancionatória: art. 273, inc. II, do Código de Processo Civil. São Paulo: Malheiros, 2006. 
LOPES DA COSTA, Alfredo Araújo. Medidas preventivas. $3^{\mathrm{a}}$ ed. São Paulo: Sugestões Literárias, 1966.

LUCON, Paulo Henrique dos Santos. Eficácia das decisões e execução provisória. São Paulo: Ed. Revista dos Tribunais, 2000.

. Tutela provisória na atualidade. In: BUENO, Cassio Scarpinella; NETO, Elias Marques de Medeiros; NETO, Olavo de Oliveira; CAZZOLINO DE OLIVEIRA, Patrícia Elias; LUCON, Paulo Henrique dos Santos (coords.). Tutela provisória no CPC: dos 20 anos de vigência do art. 274 do CPC/1973 ao CPC/2015. 2a ed. São Paulo: Saraiva Educação, 2018.

MACEDO, Elaine Harzheim. Prestação jurisdicional em sede de tutela antecedente: procedimento, estabilização da decisão e decurso do prazo de 2 (dois) anos: um novo caso de perempção? Revista de Processo, vol. 250/2015.

MACHADO, Antônio Claudio da Costa. Tutela antecipada. $3^{\text {a }}$ ed. São Paulo: Juarez de Oliveira, 1999.

. Tutela provisória: Interpretação artigo por artigo, parágrafo por parágrafo, do Livro V, da Parte Geral, e dos dispositivos esparsos do CPC em vigor que versam sobre Tutela Provisória. São Paulo: Malheiros, 2017.

MACHADO DA ROCHA, Daniel; BALTAZAR JUNIOR, José Paulo. Comentário à Lei de Benefícios da Previdência Social. $7^{\mathrm{a}}$ ed. Porto Alegre: Livraria do Advogado, Ed. Esmafe, 2007.

MARINONI, Luiz Guilherme. Antecipação da tutela. 12a ed. São Paulo: Ed. Revista dos Tribunais, 2011.

; ARENHART, Sérgio Cruz. Comentários ao Código de Processo Civil (arts. 294 ao 333). $2^{a}$ ed. São Paulo: Ed. Revista dos Tribunais, 2018.

.; MITIDIERO, Daniel. Novo código de processo civil comentado. $2^{\mathrm{a}}$ ed. São Paulo: Revista dos Tribunais, 2016.

; TESSER, Andre Luiz Bauml. Tutela cautelar e antecipação de tutela. $1^{\mathrm{a}}$ ed. São Paulo: Revista dos Tribunais, 2014.

MARQUES DE CAMPOS, Gledson; DESTEFENNI, Marcos. Tutela de urgência satisfativa autônoma. In: ARMELIN, Donaldo (coord.). Tutelas de urgência e cautelar. Estudos em homenagem a Ovídio A. Baptista da Silva. São Paulo: Saraiva, 2010.

MEDINA, José Miguel Garcia. Curso de direito processual civil moderno. $3^{\mathrm{a}}$ ed. São Paulo: Ed. Revista dos Tribunais, 2017.

MITIDIERO, Daniel. Antecipação da tutela. $3^{\text {a }}$ ed. São Paulo: Ed. Revista dos Tribunais, 2017.

MONIZ DE ARAGÃO, Egas Dirceu. Do agravo regimental. Revista de Direito Processual Civil, vol. 2. 
NERY JR., Nelson; NERY, Rosa Maria de Andrade. Comentários ao código de processo civil: Novo CPC - Lei 13.105/2015. $1^{\text {a }}$ ed. São Paulo: Revista dos Tribunais, 2015.

NEVES, Celso. Coisa julgada civil. São Paulo: Ed. Revista dos Tribunais, 1971.

NEVES, Daniel Amorim Assumpção. Manuel de direito processual civil. 10 a ed. Salvador: Juspodivm, 2018.

Preclusões para o juiz: preclusão pro iudicato e preclusão judicial no processo civil. $1^{\text {a }}$ ed. São Paulo: Método, 2004.

NUNES, Dierle; ANDRADE, Érico. Os contornos da estabilização da tutela provisória de urgência antecipatória no Novo CPC e o mistério da ausência de formação da coisa julgada. In: DIDIER JR., Fredie (coord. geral). Procedimentos especiais, tutela provisória e direito transitório. Salvador: Juspodivm, 2015.

PAGANI DE SOUZA, André; CARACIOLA, Andrea Boari; AUGUSTO DE ASSIS, Carlos; FERNANDES, Luís Eduardo Simardi; DELLORE, Luiz. Teoria geral do processo contemporâneo. $4^{\mathrm{a}}$ ed. São Paulo: Atlas, 2019.

PAIM, Gustavo Bohrer. Estabilização da tutela antecipada. Porto Alegre: Ed. Livraria do Advogado, 2012. . O référé francês. Revista de Processo, vol. 203/2012.

PAULINO DOS REIS, Dagma. O référé francês e as decisões urgentes no Brasil. In: FIDÉLIS DOS SANTOS, Ernane; WAMBIER, Luiz Rodrigues; NERY JR., Nelson; WAMBIER, Teresa Arruda Alvim (coords.). Execução civil: estudos em homenagem ao professor Humberto Theodoro Júnior. São Paulo: Ed. Revista dos Tribunais, 2007.

PEDRON, Flávio Quinaud; MILAGRES, Allan; ARAÚJO, Jéssica. A estabilização da tutela provisória de urgência antecipada antecedente e a busca para uma compreensão sistêmica: entre a monitorização e a negociação processual. Revista de Processo, vol. 268/2017.

PEIXOTO, Ravi. Enunciados FPPC. Organizados por assunto, anotados e comentados. Salvador: Juspodivm, 2018.

Por uma análise dos remédios jurídicos processuais aptos a impedir a estabilização da tutela antecipada antecedente. In: DIDIER JR., Fredie (coord. geral). Tutela provisória. Grandes temas do novo CPC. Salvador: Juspodivm, 2016.

PEREIRA, Alexandre Ferrer Silva. A efetividade da tutela antecipada de evidência no estado democrático de direito. Rio de Janeiro: Lumen Juris, 2016.

PEYRANO, Jorge W. La batalla por la medida autosatisfactiva. In: ARMELIN, Donaldo (coord.). Tutelas de urgência e cautelar. Estudos em homenagem a Ovídio A. Baptista da Silva. São Paulo: Saraiva, 2010.

PICARDI, Nicola. Manuale del processo civile. Milano: Giuffrè, 2006. 
PISANI, Andrea Proto. Verso la residualità del processo a cognizione piena? Revista de Processo, vol. 131/2006.

PUOLI, José Carlos Baptista. Os poderes do juiz e as reformas do processo civil. São Paulo: Juarez de Oliveira, 2001.

Processo e constituição: alcance amplo, mas não ilimitado, dos princípios constitucionais do processo. In: PUOLI, José Carlos Baptista; BONÍCIO, Marcelo José Magalhães; LEONEL, Ricardo de Barros (coords.). Direito processual constitucional. Brasília: Gazeta Jurídica, 2016.

. O ônus da prova e sua distribuição dinâmica no novo código de processo civil. In: O Novo Código de Processo Civil: questões controvertidas/vários autores. São Paulo: Atlas, 2015.

$\mathrm{XXXV, \textrm {n } ^ { \circ } 1 2 6 .}$

O juiz, a aplicação do Direito e o Novo CPC. Revista do Advogado, ano

O advogado e as respostas do réu. In: DIDIER JR., Fredie (coord. geral). Advocacia. Coleção Repercussões do Novo CPC. Salvador: Juspodivm, 2015.

RANGEL, Rafael Calmon. Os arts. 303 e 304 do CPC: da interpretação à aplicação. Revista de Processo, vol. 261/2016.

A estabilização da tutela antecipada antecedente nas ações de família. Revista IBDFAM, n. 16, jul/ago.2016.

REALE, Miguel. Lições preliminares de Direito. 26ª ed. São Paulo: Saraiva, 2002.

REDONDO, Bruno Garcia. Estabilização, modificação e negociação da tutela de urgência antecipada antecedente: principais controvérsias. Revista de Processo, vol. 244/2015.

Estabilização, modificação e negociabilidade da tutela de urgência antecipada antecedente: principais controvérsias. In: DIDIER JR., Fredie. (coord. geral). Tutela provisória. Coleção Grandes Temas do Novo CPC. Salvador: Juspodivm, 2016.

RICCI, Edoardo Flavio. A tutela antecipatória brasileira vista por um italiano. Trad. José Rogério Cruz e Tucci. Curitiba: Revista de Direito Processual e Civil, vol. 6/1997.

A evolução da tutela urgente na Itália. In: ARMELIN, Donaldo (coord.). Tutelas de urgência e cautelar. Estudos em homenagem a Ovídio A. Baptista da Silva. São Paulo: Saraiva, 2010.

RIBEIRO, Leonardo Ferres da Silva. Tutela provisória: tutela de urgência e tutela de evidência. $3^{\text {a }}$ ed. São Paulo: Ed. Revista dos Tribunais, 2018.

Tutela jurisdicional de urgência: regime jurídico único das tutelas cautelar e antecipada. Tese de Doutorado. Pontifícia Universidade Católica de São Paulo, 2010, 354 f.

RODRIGUES, Marcelo Abelha. Manual de direito processual civil. $6^{\mathrm{a}}$ ed. Rio de Janeiro: Forense, 2016. 
Suspensão de segurança. São Paulo: Ed. Revista dos Tribunais, 2000.

RODRIGUES, Marco Antonio. A fazenda pública no processo civil. $2^{\text {a }}$ ed. São Paulo: Atlas, 2016.

RODRIGUES, Rafael Ribeiro; THAMAY, Renan Faria Krüger. Estabilização e pedido incontroverso. Revista de Processo, vol. 268/2017.

ROJAS, Jroge A. Tutela anticipada: sistema cautelar o proceso urgente? Revista Iberoamericana de Derecho Procesal, vol. 2/2015.

SICA, Heitor Vitor Mendonça. Preclusão processual civil. 2a ed. São Paulo: Atlas, 2008.

Doze problemas e onze soluções quanto à chamada "estabilização da tutela antecipada". In: DIDIER JR., Fredie (coord. geral). Procedimentos especiais, tutela provisória e direito transitório. $2^{\mathrm{a}}$ ed. Salvador: Juspodivm, 2016.

SILVA DE LIMA, Bernardo; EXPÓSITO, Gabriela. "Porque tudo que é vivo, morre". Comentários sobre o regime da estabilização dos efeitos da tutela provisória de urgência no novo CPC. Revista de Processo, vol. 250/2015.

SOARES, Rogério Aguiar Munhoz. Tutela jurisdicional diferenciada: Tutelas de urgência e medidas liminares em geral. São Paulo: Malheiros, 2000.

TALAMINI, Eduardo. A (in)disponibilidade do interesse público: consequências processuais (composições em juízo, prerrogativas processuais, arbitragem e ação monitória). Revista de Processo, vol. 128/2005.

- Tutela de urgência no projeto de novo Código de Processo Civil: a estabilização da medida urgente e a "monitorização" do processo civil brasileiro. Revista de Processo, vol. 209/2012.

. Tutela monitória. $2^{\mathrm{a}}$ ed. São Paulo: Ed. Revista dos Tribunais, 2001.

TESSER, André Luiz Bäuml. As diferenças entre a tutela cautelar e a antecipação de tutela no CPC/2015. In: DIDIER JR., Fredie (coord. geral). Procedimentos especiais, tutela provisória e direito transitório. $2^{\mathrm{a}}$ ed. Salvador: Juspodivm, 2016.

. Tutela cautelar e antecipação de tutela: perigo de dano e perigo de demora. São Paulo: Ed. Revista dos Tribunais, 2014.

THEODORO JR., Humberto. Curso de direito processual civil, vol. I. $57^{\mathrm{a}}$ ed. Rio de Janeiro: Forense, 2016.

. Curso de direito processual civil: teoria geral do direito processual civil, processo de conhecimento e procedimento comum. 56 ${ }^{\mathrm{a}}$ ed. Rio de Janeiro: Forense, 2015.

. Processo cautelar. São Paulo: Leud, 1976.

Tutela antecipada. In: WAMBIER, Teresa Arruda Alvim (coord.). Aspectos polêmicos da antecipação de tutela. São Paulo: Ed. Revista dos Tribunais, 1997. 
$150 / 2007$.

Interpretação e aplicação das normas jurídicas. Revista de Processo, vol.

; ANDRADE, Érico. A autonomização e a estabilização da tutela de urgência no Projeto de CPC. Revista de Processo, vol. 206/2012.

VEIGA, Daniel Brajal; FONSECA, Geraldo; D'Orio, Rodrigo; FAGUNDES, Cristiane Druve Tavares; ARMELIN, Roberto. Tutela provisória: questões polêmicas. In: BUENO, Cassio Scarpinella; NETO, Elias Marques de Medeiros; NETO, Olavo de Oliveira; CAZZOLINO DE OLIVEIRA, Patrícia Elias; LUCON, Paulo Henrique dos Santos (coords.). Tutela provisória no CPC: dos 20 anos de vigência do art. 274 do CPC/1973 ao CPC/2015. 2a ed. São Paulo: Saraiva Educação, 2018.

VUITTON, Xavier. La juridiction du Président: première instance, appel, cassation: référés, requête, fond. Paris: LexisNexis, 2010.

; VUITTON, Jacques. Les référés. Procédure civile. Contentieux administratif. Procédure penale. $3^{\mathrm{a}}$ ed. Paris: LexisNexis, 2012.

WAMBIER, Luiz Rodrigues; TALAMINI, Eduardo. Curso avançado de processo civil: cognição jurisdicional (processo comum de conhecimento e tutela provisória), vol. 2. São Paulo: Ed. Revista dos Tribunais, 2018, p. 918.

WAMBIER, Teresa Arruda Alvim; CONCEIÇÃO, Maria Lúcia Lins; RIBEIRO, Leonardo Ferres da Silva; Mello, Rogerio Licastro Torres de. Primeiros comentários ao novo código de processo civil: artigo por artigo. São Paulo: Revista dos Tribunais, 2015.

WATANABE, Kazuo. Da cognição no processo civil. $2^{\mathrm{a}}$ ed. São Paulo: Centro Brasileiro de Estudos e Pesquisas Jurídicas, 1999.

Tutela antecipatória e tutela específica das obrigações de fazer e não fazer arts. 273 e 461 do CPC. In: TEIXEIRA, Sálvio de Figueiredo (coord.). Reforma do Código de Processo Civil. São Paulo: Saraiva, 1996.

YARSHELL, Flávio Luiz. Breves notas sobre a disciplina da ação rescisória no CPC 2015. In: O Novo Código de Processo Civil: questões controvertidas/vários autores. São Paulo: Atlas, 2015.

ABDO, Helena. As questões não tão evidentes sobre a tutela da evidência. In: BUENO, Cassio Scarpinella; NETO, Elias Marques de Medeiros; NETO, Olavo de Oliveira; CAZZOLINO DE OLIVEIRA, Patrícia Elias; LUCON, Paulo Henrique dos Santos (coords.). Tutela provisória no CPC: dos 20 anos de vigência do art. 274 do CPC/1973 ao CPC/2015. 2a ed. São Paulo: Saraiva Educação, 2018.

YOSHIKAWA, Eduardo Henrique de Oliveira. Tutela de urgência definitiva? Medidas autossatisfativas (Argentina), medidas provisionais (Brasil) e a proposta de estabilização da antecipação de tutela. Revista de Processo, vol. 231/2014.

VELOSO, Vitor Lanza. Tutela de urgência antecipatória e a Fazenda Pública no Novo Código de Processo Civil. In: DIDIER JR., Fredie (coord. geral). Processo $e$ Administração Pública. Coleção Repercussões do Novo CPC. Salvador: Juspodivm, 2016. 
ZAVASCKI, Teori Albino. Antecipação da tutela. $4^{\mathrm{a}}$ ed. São Paulo: Saraiva, 2005. 